\title{
Role of functional avidity in HIV-specific memory CD8 T cell effector functions
}

\author{
Tiffany Lemon*, Donna Alvino, Zaza Ndhlovu, Bruce Walker \\ From 17th International Symposium on HIV and Emerging Infectious Diseases (ISHEID) \\ Marseille, France. 23-25 May 2012
}

CD8+ T cells provide protective antiviral defense in HIV-1 infection. Although studies demonstrate which effector functions are employed, knowledge of the underlying mechanisms is lacking and inconclusive. Here, we investigate the functional avidity of CD8+ T cells, based on cytokine secretion and proliferation, to compare the effective antigen concentration required to induce each response. Our preliminary data suggests that the functional avidity of $\mathrm{CD} 8+\mathrm{T}$ cells differs based on the effector function used for measurement, indicating that the requirements for activation differ within a single CD8+ profile. We also found that elite controllers, individuals who control the virus without antiretroviral treatment, require lower avidity interactions than chronic progressors.

These and future results will help to determine optimal doses of antigens for the induction of effective responses in new vaccine formulations.

Published: 25 May 2012

doi:10.1186/1742-4690-9-S1-P26

Cite this article as: Lemon et al:: Role of functional avidity in HIV-specific memory CD8 T cell effector functions. Retrovirology 2012 9(Suppl 1):P26.

\section{Controllers Exhibit Lower Avidity}
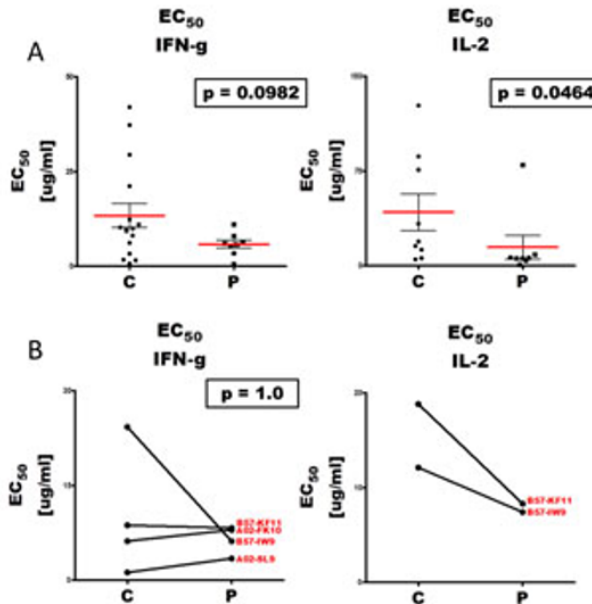

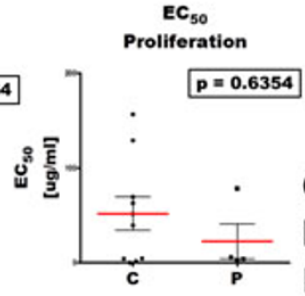

Controllers vs.

Progressors

$\mathrm{EC}_{50}$ comparison

for $A$ ) all epitopes

and $B$ ) common

epitopes.

Figure 1

* Correspondence: tlemon2@|su.edu

Louisiana State University - Dept of Biological Sciences, Baton Rouge, USA

(c) 2012 Lemon et al; licensee BioMed Central Ltd. This is an Open Access article distributed under the terms of the Creative Commons 